\title{
A LIDAR AT CLERMONT-FERRAND-FRANCE TO DESCRIBE THE BOUNDARY LAYER DYNAMICS, AEROSOLS, CIRRUS AND TROPOSPHERIC WATER VAPOR
}

\author{
J.L. Baray ${ }^{1,2}$, P. Fréville ${ }^{2}$, N. Montoux ${ }^{1}$, A. Chauvigné ${ }^{1}$, D. Hadad ${ }^{1} \&$ K. Sellegri ${ }^{1}$ \\ ${ }^{1}$ LaMP, Université Clermont Auvergne, CNRS, France, *J.L.Baray@opgc.fr \\ ${ }^{2}$ OPGC Université Clermont Auvergne, CNRS, France
}

\begin{abstract}
A Rayleigh-Mie-Raman LIDAR provides vertical profiles of tropospheric variables at ClermontFerrand (France) since 2008, in order to describe the boundary layer dynamics, tropospheric aerosols, cirrus and water vapor. It is included in the EARLINET network. We performed hardware/software developments in order to upgrade the quality, calibration and improve automation. We present an overview of the system and some examples of measurements and a preliminary geophysical analysis of the data.
\end{abstract}

\section{INTRODUCTION}

Long-term observations of water vapor, aerosols and cirrus clouds are of crucial importance to monitor the atmospheric composition and to understand the weather climate system. Satellites observations may be completed by in situ and remote sensing systems from ground based stations organized in networks such as GAW (Global Atmospheric Watch), ACTRIS (Aerosol, Clouds and Trace gases Research Infrastructure) and its LIDAR component EARLINET (European Aerosol Research LIDAR Network) [1], GRUAN (GCOS Reference Upper Air Network) or NDACC (Network for the Detection of Atmospheric Composition Change).

A Rayleigh-Mie-Raman LIDAR system is in operation since 2008 at Clermont-Ferrand and provides regular tropospheric profiles of water vapor, aerosols and cirrus clouds. It is also used to estimate the aerosol boundary layer height and indicate if the PUY global GAW station is in the mixing layer or in the free troposphere. Here we present a short technical overview of the LIDAR system operating at Clermont-Ferrand, work of calibration and data quality assurance mainly performed in the framework of EARLINET and examples of measurements in their geophysical context.

\section{DESCRIPTION OF THE LIDAR SYSTEM}

The system was designed by Gordien Strato and built by Raymetrics. It uses a Quantel CFR400 laser. The optical part is deployed outside, on the roof over the room hosting the computer and electronic device (Figure 1). The main technical characteristics are given in the Table 1.

The optical part containing the laser, the beam expender, the telescope and the optical box for the receiving wavelength separation using beamsplitters is thermoregulated, and protected by a glass. This glass allows operation in any weather condition, without modifying the polarization of emitted and received light. An automatic labview acquisition software based on the signals discriminates several situations such as "weak signal", "clouds", or "normal conditions of measurements". The system can work 24 hours a day, 7 days a week, if the conditions are good, and manage stop/restart automatically in case of bad weather conditions. Details on the algorithm and data processing are given in [2].

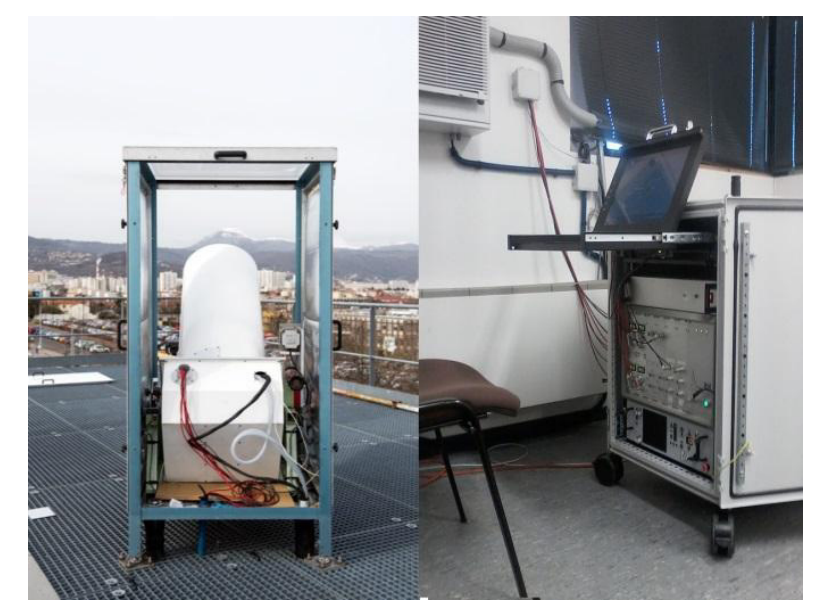

Figure 1: Optical (left, () Cyril Fresillon) and electronical (right $\odot$ Jean-Luc Baray) parts of the LIDAR system. 
Table 1 Main technical characteristics of the LIDAR

\begin{tabular}{|l|l|}
\hline Laser & $\mathrm{Nd}: Y a g$ \\
\hline Nominal energy & $\begin{array}{l}60 \mathrm{~mJ} \text { per pulse at 355 } \\
\mathrm{nm}\end{array}$ \\
\hline Frequency & $10 \mathrm{~Hz}$ \\
\hline $\begin{array}{l}\text { Beam diameter after } \\
\text { expander }\end{array}$ & $50 \mathrm{~mm}$ \\
\hline Beam divergence & $0.14 \mathrm{mrad}$ \\
\hline Reception channels & $\begin{array}{l}\text { Elastic } \perp: 354.7 \mathrm{~nm} \\
\text { Elastic // } 354.7 \mathrm{~nm} \\
\text { Raman } \mathrm{N}_{2}: 386.6 \mathrm{~nm} \\
\text { Raman } \mathrm{H}_{2} \mathrm{O}: 407.5 \mathrm{~nm}\end{array}$ \\
\hline Telescope diameter & $400 \mathrm{~mm}$ \\
\hline Field of view & 0.25 to $1 \mathrm{mrad}$ \\
\hline Partial / Full Overlap & $500 \mathrm{~m} / 1100 \mathrm{~m}$ \\
\hline Detectors & $\begin{array}{l}\text { Hamamatsu } \\
\text { Photomultipliers }\end{array}$ \\
\hline Vertical Sampling & $7.5 \mathrm{~m}$ \\
\hline
\end{tabular}

\section{NETWORKS}

At the national French level, the LIDAR system has been involved in the SOERE ROSEA, ORAURE, ATMOS, and now in the research infrastructure ACTRIS-FR. Data (range corrected signals, level 1 profiles) are transmitted in real time to the French AERIS- ICARE data center, in the framework of ACTRIS-FR. At the European level, we participate to the EARLINET network and are involved in the ACTRIS-2 WP2. In this framework, our action consists in:

- Providing regularly aerosols backscattering coefficient profiles to different categories of the EARLINET database (climatology, cirrus, calipso overpasses...);

- Carrying out regular quality assurance tests on the instrument. Those tests (dark measurements, telecover tests, depolarisation calibrations and Rayleigh fit checks) are used (i) to optimize the alignment procedure, (ii) to check regularly the LIDAR signals quality and (iii) to determine some instrumental correction factors for the processing. They are submitted at least once a year to LIDAR calibration center (lical) in Bucharest.

- Participating to network measurement campaigns such as the SCC (single calculus chain) exercise from 9 to 12 July 2012, during a Saharian dust intrusion event over Europe [3].

\section{EXAMPLES OF MEASUREMENTS}

\subsection{WATER VAPOR PROFILES AND STRATOSPHERE-TROPOSPHERE EXCHANGE}

The water vapor retrieval is based on the fact that in the troposphere, $\mathrm{N}_{2}$ is in a constant proportion of dry air. The mixing ratio of water vapor is then derived from the ratio between the $\mathrm{H}_{2} \mathrm{O}$ and the $\mathrm{N}_{2}$ Raman backscattered signals. Independent water vapor measurement or model profile has to be used to calibrate the LIDAR mixing ratio profile. The use of GPS columns at the top of the puy de Dôme station is currently evaluated but the GPS station of puy de Dôme is distant of $12 \mathrm{~km}$ from the LIDAR. Unfortunately, no collocated radiosonde measurement is routinely performed at this site. Consequently, the calibration procedure has been performed normalizing by water vapor mixing ratios from the ECMWF ERA-Interim reanalysis between 3 and $5 \mathrm{~km}$ height.

Since 2013, more than 100 night-time profiles per year can reach more than $4 \mathrm{~km}$ high. This number increases from year to year as the system improves and reaches more than 195 night-time profiles in 2015. An interesting example of water vapor measurement was during the night between 29 and 30 January 2013. Figure 2 is the time series of one minute water vapor profiles.

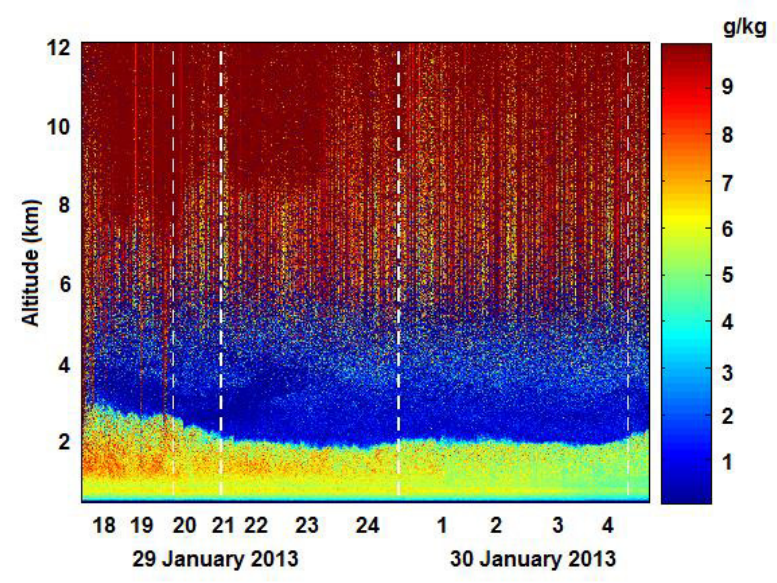

Figure 2: Time series of one minute water vapor profiles during the night between 29 and 30 January 2013. The time scale is not regular because some cloudy files have been removed.

It shows a humid layer near the ground, capped by a dry layer. The limit between the two layers 
varies during the night from 2 to $3 \mathrm{~km}$. The upper limit of the profiles is around 5-6 km.

By integrating all the files obtained during this night, the upper limit is extended to $8 \mathrm{~km}$ (Figure 3 ). This allows a dry layer to be detected between 5 and $7 \mathrm{~km}$. Four-day backtrajectories suggest a polar and stratospheric origin for a major part of the air masses arriving over Clermont-Ferrand during this case study (Figure 4). The dynamical analysis based on ECMWF ERA-Interim, and Reverse Domain Filling calculations confirm that this stratosphere-troposphere exchange event was associated to the polar jet stream [4].

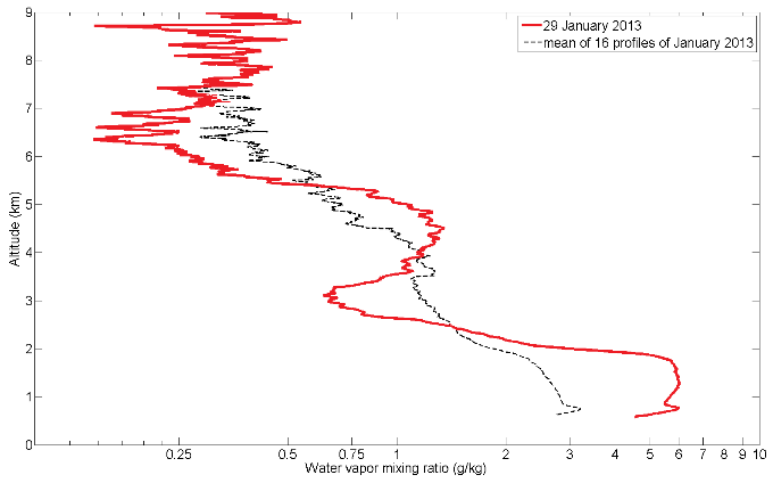

Figure 3: Profile calculated by integrating the whole night between 29 and 30 January 2013 (in red), compared to the mean of 16 profiles of January 2013 (black dashed line)

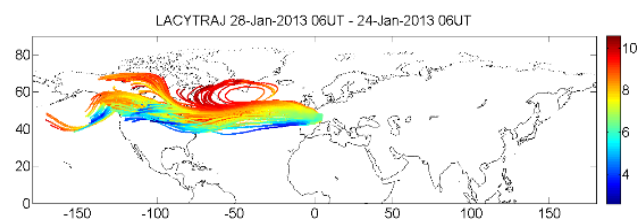

Figure 4: Four-day backtrajectories arriving over Clermont-Ferrand during the case study, calculated with the LACYTRAJ model [5]. Colors indicate the altitude in $\mathrm{km}$.

\subsection{AEROSOLS PROFILES, CIRRUS AND MIXING LAYER HEIGHT}

Rayleigh-Mie channels allow to calculate backscattering coefficient profiles by applying Fernald-Klett inversion on range corrected signals $\left(\operatorname{Pr}^{2}\right)$ using specific LIDAR ratios. This methodology allowed to characterize the Eyjafjallajökull volcanic plume in April-May 2010 , in combination with in situ measurements at the microphysical station at the top of the puy de Dôme [6].
Natural and anthropogenic aerosols are most concentrated in the atmospheric mixing layer, where they are removed by rain, particle coagulation, or sedimentation. In the free troposphere, aerosol particles are subjected to fewer removal processes increasing their lifetime and impact on the climate. It is then important to survey the evolution of the limit between the mixing layer and the free troposphere. One way to do this is to use the wavelet covariance transform technique on backscattered LIDAR profiles. This methodology shows that the mixing layer height may vary a lot during one day (Figure 5). In the example of 4 May 2016, variations during the night are due to the difficulty for the algorithm to distinguish the nighttime residual layer and the mixing layer. During daytime, the mixing layer height is better retrieved and increases due to convective uplift.

In combination with is-situ observations at the top of the puy de Dôme station, the lidar has also allowed to evidence feeding processes of the free troposphere with aerosol particles from the mixing layer during a cold period in February 2012 [7].
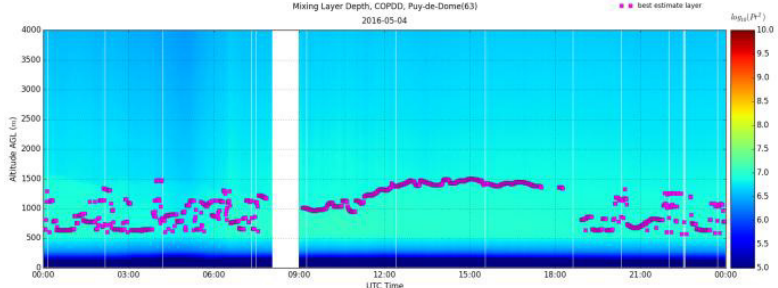

Figure 5: Example of mixing layer height estimation, on 4 May 2016. Extracted from the ICARE on-line data archive (http://www.icare.univ-lille1.fr/).

COPDD Puy-De-Dome, OPGC/RM_LR112 Level 1, 27 Sep 2014, cbh

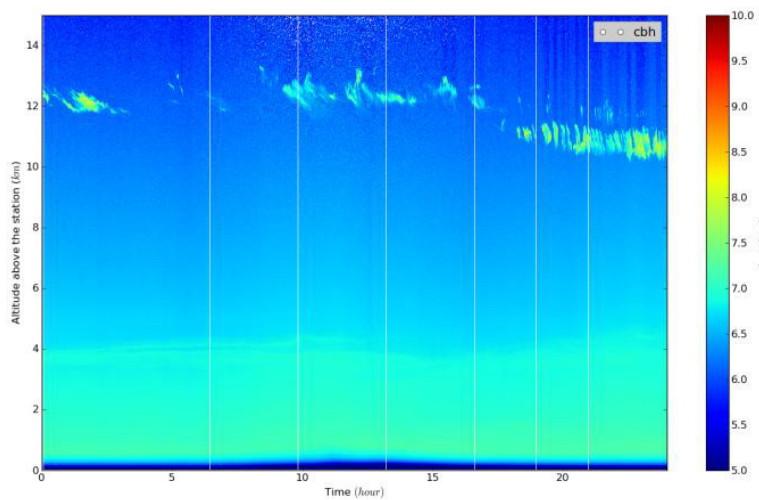

Figure 6: Time series of $\log \left(P^{2}\right)$ during the 27 September 2014. Extracted from the ICARE on-line data archive. 
A special day presenting aerosols near the ground and cirrus cloud near the tropopause on 27 September 2014 is presented on Figure 6.

The aerosol layer is observed below 4-5 km with high values of $\mathrm{Pr}^{2}$. A cirrus event appears also between 11 and $13 \mathrm{~km}$, in addition to the aerosol event.

The origin of the aerosol layer could be a mix of volcanic emissions from the Bardabunga $\left(64^{\circ} \mathrm{N}\right.$, $17^{\circ} \mathrm{W}$ ) eruption, and biomass burning in North America.

\section{CONCLUSIONS AND FUTURE PLANES}

We provided a technical description of the Rayleigh-Mie-Raman LIDAR in operation at Clermont-Ferrand (France) since 2008, and examples of measurements of tropospheric aerosols, cirrus and water vapor profiles. The continuation of routine measurements in the long term is very important for climate issue and we plan to ensure it.

In operation since now 9 years, the laser does not currently provide the nominal power despite regular maintenance operations. We plan to change it as soon as the budget will be completed. It could be the first step of a multi-year investment program whose objective is an increasing evolution of our LIDAR system, with 3 wavelengths in emission and an additional nearrange channel to better document the boundary layer dynamics.

\section{ACKNOWLEDGEMENTS}

This work is dedicated to Vincent Giraud (19652009), who was involved in LIDAR activities at Clermont-Ferrand, at the beginning. The LIDAR system is operated by OPGC observatory and LaMP research laboratory. It has been supported by Clermont-Auvergne, CNRS, CNES, ROSEAORAURE and now ACTRIS-FR, and regional founds (FEDER, CPER, Region Auvergne). We acknowledge the ICARE service center for furnishing the BASIC/STRAT figures. We thank all the people involved in CO-PDD instrumented site, and in the LIDAR data processing (M. Hervo, G. Payen, D. Dionisi).

\section{References}

[1] Pappalardo, G.; Amodeo, A.; Apituley, A.; Comeron, A.; Freudenthaler, V.; Linné, H.; Ansmann, A.; Bösenberg, J.; D’Amico, G.; Mattis, I.; et al. EARLINET: Towards an advanced sustainable European aerosol LIDAR network. Atmos. Meas. Tech., 7, 2389-2409, 2014.

[2] Fréville P., N. Montoux, J.-L. Baray, A. Chauvigné, F. Réveret, M. Hervo, D. Dionisi, G. Payen, K. Sellegri, Lidar developments at Clermont-Ferrand - France for atmospheric observation, Sensors, 15, 3041-3069; doi:10.3390/s150203041, 2015.

[3] Sicard, M., et al.: EARLINET: potential operationality of a research network, Atmos. Meas. Tech., 8, 4587-4613, doi:10.5194/amt-84587-2015, 2015.

[4] Baray J.-L. , Y. Pointin, J. Van Baelen, M. Lothon, B. Campistron, J.-P. Cammas, Olivier Masson, D. Hadad, A. Colomb, C. Hervier, Y. Bezombes, C. Duroure, and F. Tridon, Case study and climatological analysis of upper tropospheric jet stream and stratospheretroposphere exchanges using VHF profilers and radionuclide measurements in France, submitted, Journal of Applied Meteorology and Climatology, 2016.

[5] Clain G., J.-L. Baray, R. Delmas, P. Keckhut, J.-P. Cammas, A lagrangian approach to analyse the tropospheric ozone climatology in the tropics: Climatology of Stratosphere Troposphere exchange at Reunion Island, Atmospheric Environment, 44, 968-975, 2010.

[6] Hervo, M., et al. Physical and optical properties of 2010 Eyjafjallajökull volcanic eruption aerosol: Ground-Based, LIDAR and airborne measurements in France. Atmos. Chem. Phys., 12, 1721-1736, 2012.

[7] Freney E., K. Sellegri, E. Asmi, C. Rose, A. Chauvigne, J.-L. Baray, A. Colomb, M. Hervo, N. Montoux, L. Bouvier, D. Picard, Experimental evidence of the feeding of the free troposphere with aerosol particles from the mixing layer, Aerosol and Air Quality Research, 16 : 702-716, doi: 10.4209/aaqr.2015.03.0164, 2016. 